\title{
Pesquisas de Avaliação e Confidencialidade da Informação: Limites e Conflitos
}

Ana Karine Pereira ${ }^{1}$ Pedro Stoeckli Pires ${ }^{2}$ Alexandro Pinto ${ }^{3}$

1 Mestre e Doutora em Ciência Política pela Universidade de Brasília, é Analista Técnico de Políticas Sociais em exercício na Secretaria de Avaliação e Gestão da Informação - SAGI/MDS.

2 Mestre e Doutorando em Antropologia Social na Universidade de Brasília, é Analista Técnico de Políticas Sociais em exercício na Secretaria de Avaliação e Gestão da Informação - SAGI/MDS.

3 Diretor de Avaliação do Ministério de Desenvolvimento Social e Combate à Fome (DA/SAGI/MDS) 


\section{Resumo}

ESTE ARTIGO PROPÕE APRESENTAR OS ELEMENTOS JURÍDICOS, NORMATIVOS, O DEBATE ACADÊMICO E OS ENTENDIMENTOS E PRÁTICAS DOS ÓRGÃOS OFICIAIS DE ESTATÍSTICA REFERENTES AOS PARÂMETROS ÉTICOS DAS PESOQUISAS DE AVALIAÇÃO E DE MONITORAMENTO DE POLÍTICAS PÚBLICAS - COM ÊNFASE NOS SEUS ASPECTOS DE PRIVACIDADE, ANONIMATO E CONFIDENCIALIDADE. PENSADA INICIALMENTE PARA A ÁREA DA BIOMEDICINA, A APLICAÇÃo DA LEGISLAÇÃo ESTABELECE PRINCÍPIOS ÉTICOS PARA A REALIZAÇÃO DE PESOUUISAS COM SERES HUMANOS E OS PRINCÍPIOS DAS ESTATÍSTICAS OFICIAIS DO Sistema NACIONAL DE EstatíSTICA, OUUE VALORIZAM O SIGILO E A CONFIDENCIALIDADE. ESSE POSTULADO TEM ESTIMULADO DIVERSAS DISCUSSÕES NAS PESOUUISAS NA ÁREA DE CIÊNCIAS SOCIAIS APLICADAS, ESPECIALMENTE OUUANDO SÃO UTILIZADAS METODOLOGIAS OUALITATIVAS. ISSO OCORRE POROUUE A OBSERVÂNCIA DESSES PRINCÍPIOS, NESSE TIPO DE PESOUUISA, GERA ALGUNS CONFLITOS RELACIONADOS COM A EXIGÊNCIA DE RESPEITO À CONFIDENCIALIDADE E AO SIGILO E A NECESSIDADE DE UTILIZAR A INFORMAÇÃO INSTRUMENTAL A FIM DE EMBASAR UMA POSTURA INTERVENIENTE, EM OUE PROBLEMAS DETECTADOS SEJAM CORRIGIDOS. DESSA FORMA, O OBJETIVO DESTE ARTIGO É CONTRIBUIR PARA ESSE DEBATE AO DETALHAR OS ENTENDIMENTOS E AS PRÁTICAS OUE DEVEM SER APLICADOS AOS ÓRGÃOS DA ADMINISTRAÇÃO PÚBLICA FEDERAL OUUE FAZEM PARTE DO SISTEMA NACIONAL DE ESTATÍSTICA.

\section{Abstract}

THIS PAPER PRESENTS LEGISLATIONS, ACADEMIC DISCUSSIONS, AND THE UNDERSTANDINGS AND PRACTICES OF THE OFFICIAL STATISTICAL AGENCIES RELATED TO THE ETHICAL PARAMETERS THAT REGULATE THE EVALUATION AND MONITORING OF PUBLIC POLICIES RESEARCH - WITH EMPHASIS ON ASPECTS OF PRIVACY, ANONYMITY AND CONFIDENTIALITY. THE ENFORCEMENT OF THE LEGISLATIONS THAT ESTABLISHES ETHICAL PRINCIPLES FOR CONDUCTING RESEARCH WITH HUMAN BEINGS - WHICH WERE ELABORATED IN THE FIRST PLACE TO REGULATE RESEARCHES IN THE BIOMEDICINE FIELD - AND THE OFFICIAL STATISTICS' PRINCIPLES of the National Statistical System, that VALUE SECRECY AND CONFIDENTIALITY, HAVE STIMULATED SEVERAL DISCUSSIONS IN THE APPLIED SOCIAL SCIENCES FIELD, ESPECIALLY WHEN THESE PRINCIPLES ARE EXPECTED TO REGULATE QUALITATIVE RESEARCHES. IN THIS KIND OF RESEARCH, THE COMPLIANCE WITH THESE PRINCIPLES CREATES SOME CONFLICTS RELATED TO THE REQUIREMENT TO RESPECT CONFIDENTIALITY AND SECRECY AND THE NEED TO USE THE INSTRUMENTAL INFORMATION TO SUPPORT AN INTERVENING POSITION, IN WHICH THE PROBLEMS IDENTIFIED ARE CORRECTED. THUS, THE AIM OF THIS PAPER IS TO CONTRIBUTE TO THIS DISCUSSION BY EXPLORING THE UNDERSTANDINGS AND PRACTICES THAT SHOULD BE APPLIED TO THE FEDERAL PUBLIC ADMINISTRATION AGENCIES THAT ARE PART OF THE NATIONAL STATISTICAL SYSTEM.

\section{PALAVRAS-CHAVE:}

Confidencialidade. Sigilo. Pesquisas de Avaliação e de Monitoramento.

Revista Brasileira de Monitoramento e Avaliação | Número 7 | Janeiro-Junho de 2014 


\section{Introdução}

Este artigo propõe levantar alguns elementos jurídicos, normativos e de discussão pertinentes aos parâmetros éticos das pesquisas de avaliação e de monitoramento de políticas públicas, em especial no que concerne a privacidade, ao anonimato e a confidencialidade.

Conforme explica Jannuzzi, atividades de monitoramento e avaliação consistem em "registro, produção, organização, acompanhamento e análise crítica de informações resultantes da Gestão de Políticas Públicas, para identificação de demandas sociais, desenho, seleção, implementação e avaliação de soluções" ${ }^{\prime \prime}$. Nesse sentido, apesar de serem realizadas por meio de métodos científicos, as pesquisas de avaliação e de monitoramento diferem das pesquisas acadêmicas, pois têm em sua origem demandas de obtenção de respostas para problemas específicos pertinentes às políticas públicas.

Sobre a experiência de atuação em avaliação e monitoramento ${ }^{5}$ no Ministério do Desenvolvimento Social e Combate à Fome (MDS), Vaitsman, Rodrigues e Paes-Souza afirmam:

A avaliação costuma ser realizada por meio de estudos específicos que procuram analisar aspectos como relevância, eficiência, efetividade, resultados, impactos ou a sustentabilidade de programas e políticas, segundo aquilo que foi definido em seus objetivos. Seu objetivo é melhorar as atividades em andamento e dar subsídios para o planejamento, a programação e a tomada de decisões futuras. ${ }^{6}$

Em função da complexidade e das múltiplas variáveis (históricas, econômicas, demográfi- cas, sanitárias, culturais etc.) que compõem as diferentes realidades sociais, os estudos de avaliação e monitoramento buscam arranjos interdisciplinares que combinem metodologias quantitativas e qualitativas para que seja possível correlacionar distintas dimensões de um programa ou política. Assim, nesse tipo de pesquisa, faz-se pertinente a máxima de que problemas complexos demandam, muitas vezes, investigações e soluções complexas.

Exemplos recentes de pesquisas encomendadas e executadas pela Secretaria de Avaliação e Gestão da Informação (SAGI) reforçam essa característica. Em um deles, foi encomendado um estudo transversal de base populacional, de tipo censitário, que utilizou métodos quantitativos de coleta de dados para analisar a situação de segurança alimentar e nutricional em comunidades quilombolas tituladas. ${ }^{7}$ No caso, recorreu-se à aplicação de questionários estruturados e à coleta de dados antropométricos de todas as crianças menores de 5 anos de idade, notadamente em um grupo populacional culturalmente diferenciado.

Já em outra pesquisa de caráter confidencial e em fases iniciais, o objetivo é o levantamento e a análise de dados que permitam a caracterização ao longo do tempo da população em situação de pobreza em dois contextos - o Semiárido brasileiro e o Sudeste metropolitano -, particularmente no que se refere à composição e à volatilidade da renda das famílias, às estratégias de inserção produtiva e ao acesso a serviços públicos. Assim, essa caracterização leva à interação e ao contato com os grupos pesquisados ao longo de um 
tempo maior, o que traz desafios próprios dessa metodologia.

Nos exemplos acima citados, as pesquisas de avaliação passam por categorias de populações que incitam cuidados particulares, tais como no caso de grupos específicos, ou com pessoas sem capacidade de autodeterminação, como é o caso de crianças. Além dessas duas pesquisas, as avaliações realizadas utilizaram metodologias e técnicas diversas, muitas vezes conjugadas: antropometria, desenhos quase-experimentais, estudos transversais, grupos focais, etnografia, painel longitudinal, Survey, entre outros.

Os aspectos éticos de pesquisas que envolvem seres humanos têm sido uma preocupação constante desde as primeiras regulamentações sobre o assunto, cujo marco é o Código de Nuremberg de 1947. Essas normativas iniciais tinham como foco os estudos na área da biomedicina e deram atenção especial à necessidade do respeito ao sigilo, à individualidade e à privacidade. No Brasil, grande parte dessas orientações internacionais foi incorporada pela Resolução no 196/96 do Conselho Nacional de Saúde, que estendeu as diretrizes para a realização de pesquisas na área da saúde para todos os estudos que envolvem seres humanos. Na administração pública federal, o coordenador do Sistema Nacional de Estatística (SNE), do Instituto Brasileiro de Geografia e Estatística (IBGE), tem enfatizado o predomínio do sigilo e da confidencialidade, o que foi regulamentado pela Lei n 5.534, de 14 de novembro de 1968, e reforçado no sexto princípio dos Princípios Fundamentais das Estatísticas Oficiais.

Apesar da importância incontestável da confidencialidade e do sigilo para a realização de pesquisas na área das ciências humanas, sua

$4 \quad$ JANUZZI, 2014a, p. 8.

50 artigo $4^{\circ}$ da Portaria n 329/2006 do MDS estabelece que "são consideradas ações de avaliação qualquer estudo ou pesquisa referente aos programas e ações que tenha um dos seguintes objetivos: I - análise da implementação de programas e ações; II - análise de resultados imediatos dos programas e ações; III - análise de impactos ou efeitos dos programas e ações; IV análise da eficiência, da equidade, da eficácia ou da efetividade de programas e ações; $V$ - análise do perfil dos beneficiários dos programas e ações; VI - elaboração de diagnósticos de perfil da demanda; VII - avaliação da satisfação de beneficiários/usuários; VIII - avaliação da qualidade dos serviços prestados; e IX - elaboração de estudos de 'linha de base'".

6 VAITSMAN, RODRIGUES \& PAES-SOUZA, 2006, p. 23.

7 "Pesquisa de Avaliação da Situação de Segurança Alimentar e Nutricional em Comunidades Quilombolas Tituladas". Disponível em: <http://aplicacoes.mds.gov.br/sagirmps/simulacao/sum_executivo/pg_principal.php?url=busca_por_id\&id_sum=135>.

Revista Brasileira de Monitoramento e Avaliação | Número 7 | Janeiro-Junho de 2014 
aplicação em estudos que utilizam metodologias interdisciplinares e qualitativas, como é o caso da SAGI, traz algumas questões. Alguns autores ressaltam que a rigidez das diretrizes de confidencialidade e do sigilo, pensadas originalmente para aplicação em pesquisas biomédicas, cria obstáculos para a realização de estudos nas ciências sociais. ${ }^{8}$ Além disso, as legislações existentes deixam lacunas em relação ao papel do pesquisador, que possui uma abordagem qualitativa de estudo. Questões sobre em quais situações seria ético revelar o nome da fonte pesquisada, se a confidencialidade se mantém como prioridade em estudos que revelam práticas ilegais ou de violação de direitos, entre outras, não são facilmente respondidas se considerarmos somente o debate pertinente às áreas biomédicas.

Dessa forma, a aplicação dos princípios de sigilo e de confidencialidade em pesquisas qualitativas na área das ciências sociais aplicadas causa uma série de tensões. O conflito entre o respeito a esses princípios e a necessidade de utilizar a informação instrumental a fim de embasar uma postura interveniente, em que problemas detectados sejam corrigidos, requer um debate aprofundado para que se tenha clareza sobre qual é o papel das agências de pesquisa e do pesquisador. Assim, este artigo possui como objetivo central detalhar esse debate, contribuindo para a construção de um entendimento sobre o assunto. É dada atenção especial ao papel e às responsabilidades das agências que realizam pesquisas nas áreas de avaliação e de políticas sociais, com ênfase na SAGI. Se considerarmos que as questões suscitadas por demandas de avaliação dão espaço a respostas amplas, inclusive com possíveis denúncias, deve o pesquisador ser um mero informante dos dados coletados ou deve ele intervir na realidade estudada? Considerando que servidores têm seu exercício estipulado por legislação própria, como agir em casos em que se identificam situações de violação de direitos humanos? Deve-se utilizar o parâmetro legal para decidir sobre a quebra do sigilo e do anonimato, ou devem-se considerar outras dimensões para além das questões legais? Buscamos, a seguir, contribuir para o entendimento dessas questões.

\section{A regulamentação de pesquisas com seres humanos e seus desafios nas ciências humanas}

A preocupação com os aspectos éticos no planejamento e na execução de pesquisas científicas surgiu, no âmbito internacional, após a Segunda Guerra Mundial, como uma reação às atrocidades racistas e aos projetos eugênicos dos nazistas. ${ }^{9}$ A primeira regulamentação sobre o tema data de 1947, com a aprovação do Código de Nuremberg, que estabelece que uma pesquisa somente terá validade ética quando as pessoas que a ela se submeteram tiverem dado previamente seu consentimento. É importante ressaltar que esses debates iniciais sobre ética e pesquisa se restringiram à biomedicina, que tem liderado as iniciativas nessa área. Nas palavras de Dallari: "A bioética ou a ética aplicada aos sistemas de saúde foi, sem dúvida, o ramo da ética aplicada que mais se desenvolveu, considerando-se o número de eventos, de publicações, de documentos internacionais e de disciplinas acadêmicas a ela dedicados". ${ }^{10}$ 
Após a aprovação do Código de Nuremberg, outras normativas importantes foram estabelecidas, como a Declaração de Helsinque (1964) e as Diretrizes Internacionais Propostas para a Pesquisa Biomédica em Seres Humanos (1981), da Organização Mundial da Saúde (OMS) e do Conselho de Organizações Internacionais de Ciências Médicas (Coicim). ${ }^{11}$ As novas legislações estimularam o surgimento de comitês de ética em pesquisa, inicialmente nos Estados Unidos da América, na década de 1960, que se limitavam a regular pesquisas na área da saúde. ${ }^{12} \mathrm{~A}$ Declaração de Helsinque destacou a necessidade do respeito individual na realização de pesquisas e já revelava uma grande preocupação com a questão da confidencialidade ao estabelecer os princípios que se tem hoje sobre o tema - como o consentimento informado ao participante, o cuidado com riscos e danos ao pesquisado e o sigilo e o respeito à individualidade e à privacidade. Dallari ressalta que o cuidado com a confidencialidade dos dados foi reforçada nas Diretrizes Éticas Internacionais para a Pes- quisa Envolvendo Seres Humanos, elaboradas pelo Council for International Organizations of Medical Sciences (Cioms), em 1993. ${ }^{13}$

No Brasil, os debates sobre ética em pesquisa foram influenciados pelas normativas internacionais citadas acima e tiveram início no Conselho Federal de Medicina. Na década de 1980, algumas regulamentações foram aprovadas no sentido de criar diretrizes relacionadas a ética em pesquisas da área de saúde. 0 marco normativo sobre o assunto é a Resolução no 196/96 do Conselho Nacional de Saúde (CNS), que estabeleceu regras para serem seguidas na formulação, na execução e no acompanhamento de pesquisas no país. A grande inovação da Resolução é que ela estabelece normas não apenas para pesquisas de saúde, mas para qualquer pesquisa que envolva seres humanos. ${ }^{14}$ Iniciava-se então a tendência da área da saúde de "estender seus tendões por disciplinas e lógicas que não the são peculiares", ${ }^{15}$ criando vários atritos e transformando a ética em sinônimo de procedimentos éticos.

8 BEVILAQUA, 2010; e BARBOSA \& SOUZA, 2008.

9 MINAYO, 2008.

11 BEVILAOUA, 2010; e BARBOSA \& SOUZA, 2008.

12 BARBOSA \& SOUZA, 2008; e DALLARI, 2008.

13 DALLARI, 2008.

14 BARBOSA \& SOUZA, 2008; e DINIZ \& GUERREIRO, 2008.

15 MINAYO, 2008, p. 16.

Revista Brasileira de Monitoramento e Avaliação | Número 7 | Janeiro-Junho de 2014 
No campo da confidencialidade, as Resoluções n 196/96 e n 466/2012 estabelecem algumas diretrizes importantes, como a seção III da Resolução nº 196/96:

i) Prever procedimentos que assegurem a confidencialidade e a privacidade, a proteção da imagem e a não estigmatização dos participantes da pesquisa, garantindo a não utilização das informações em prejuízo das pessoas e/ou das comunidades, inclusive em termos de autoestima, de prestígio e/ou de aspectos econômico-financeiros; [...]

m) comunicar às autoridades competentes, bem como aos órgãos legitimados pelo Controle Social, os resultados e/ou achados da pesquisa, sempre que estes puderem contribuir para a melhoria das condições de vida da coletividade, preservando, porém, a imagem e assegurando que os participantes da pesquisa não sejam estigmatizados; [...]

q) utilizar o material e os dados obtidos na pesquisa exclusivamente para a finalidade prevista no seu protocolo, ou conforme o consentimento do participante;

E a seção IV:

e) garantia de manutenção do sigilo e da privacidade dos participantes da pesquisa durante todas as fases da pesquisa;

IV.7 - Na pesquisa que dependa de restrição de informações aos seus participantes, tal fato deverá ser devidamente explicitado e justificado pelo pesquisador responsável ao Sistema CEP/CONEP. Os dados obtidos a partir dos participantes da pesquisa não poderão ser usados para outros fins além dos previstos no protocolo e/ou no consentimento livre e esclarecido.

A necessidade do "consentimento livre e esclarecido" também é previsto pelas Resoluções n 196/96 e n 466/2012 do CNS, sendo definido nesta última, em II.5, como:

[a] anuência do participante da pesquisa e/ou de seu representante legal, livre de vícios (simulação, fraude ou erro), dependência, subordinação ou intimidação, após esclarecimento completo e pormenorizado sobre a natureza da pesquisa, seus objetivos, métodos, benefícios previstos, potenciais riscos e o incômodo que esta possa acarretar.

Esse consentimento representa mais um instrumento de proteção do entrevistado e um mecanismo que permite a confidencialidade, já que os dados obtidos na pesquisa não podem extrapolar o que é neles estabelecido.

Na administração pública federal, os órgãos que trabalham com levantamento de dados e realização de pesquisas têm feito esforços para incorporar a regulamentação sobre ética e pesquisa em suas normativas internas. Por exemplo, o IBGE lançou o Código de Ética Profissional do Servidor Público do IBGE, em que há uma clara preocupação com a confidencialidade ao vedar a disponibilização "de informações de caráter sigiloso e confidencial sobre pessoas físicas ou jurídicas, bem como antecipar resultados de pesquisas à sua divulgação oficial, exceto quando autorizado" (seção III). Por outro lado, o Código também estabelece como dever do servidor denunciar ato ou fato contrário ao interesse públi- 
co. Diante disso, surge a dúvida se o servidor deve reportar ato contrário ao interesse público mesmo que isso implique a quebra de informações confidenciais.

De forma geral, em pesquisas na área de humanidades, a aplicação da regulamentação sobre confidencialidade não tem sido tarefa simples. Diniz e Guerreiro revelam uma polarização do campo da ética em pesquisas nos últimos trinta anos: de um lado, alguns pesquisadores resistem ao modelo de revisão ética inspirado na pesquisa biomédica como válido para todas as áreas de pesquisa; de outro, estudiosos do assunto ignoram as peculiaridades da pesquisa social e defendem que as regras adotadas pelos comitês de ética traduzem os princípios que devem conduzir a pesquisa científica em qualquer área do conhecimento. ${ }^{16}$

No Brasil, este debate foi intensificado nos anos 2000 e é marcado pela resistência à incorporação da pesquisa social ao sistema de revisão ética instituído pelas Resoluções $n^{\circ}$ 196/96 e no 466/2012. Existe, assim, um intenso debate sobre a pertinência da Resolu- ção n 196/96 como norteadora de pesquisas qualitativas na área de humanidades. Um primeiro ponto levantado pelos estudiosos é que, enquanto a normativa é clara quanto aos procedimentos médicos, ela deixa várias lacunas em relação às pesquisas em ciências humanas. Outro argumento é que, como as pesquisas sociais estudam os indivíduos em seu contexto social amplo, exige-se um relacionamento próximo entre pesquisador e investigador que não é contemplado pelas rígidas diretrizes de confidencialidade e privacidade. ${ }^{17}$

Assim, de acordo com Diniz e Guerreiro, o enquadramento das técnicas qualitativas nas regras dos comitês de ética configura-se como um desafio por causa da subjetividade e da reciprocidade inerentes a essas pesquisas e por causa da relação simbólica estabelecida entre investigadores e participantes de pesquisa. ${ }^{18} \mathrm{Na}$ mesma linha, Bevilaqua afirma que "a formalização normativa de diretrizes oriundas de um universo particular - e que nele encontram seus fundamentos e condições de operacionalização - tem produzido barreiras concretas para a pesquisa nas ciências humanas e sociais". ${ }^{19}$

\footnotetext{
16 DINIZ \& GUERREIRO, 2008.

17 BARBOSA \& SOUZA, 2008.

18 DINIZ \& GUERREIRO, 2008.

19 BEVILAQUA, 2010, p. 74.
}

Revista Brasileira de Monitoramento e Avaliação | Número 7 | Janeiro-Junho de 2014 
Esses questionamentos levaram à realização, em 2006, da Reunião sobre Ética em Pesquisa Qualitativa, na cidade do Guarujá. O relatório proveniente da reunião apontava a necessidade da adequação da legislação vigente a pesquisas sociais, já que estas possuem um caráter diferente. Um dos temas mais discutidos se refere à privacidade, ao anonimato e à confidencialidade. Nas pesquisas qualitativas, a não exposição do pesquisado ou do entrevistado tem como foco não apenas sua proteção, mas também envolve uma avaliação sobre os benefícios que sua exposição ou não exposição podem representar em um contexto específico. ${ }^{20}$

Diniz e Guerreiro (2008) ressaltam que, ao contrário das pesquisas biomédicas, as pesquisas sociais envolvem um risco mínimo aos participantes no momento de sua realização. Isso ocorre porque é na fase de divulgação dos resultados que os desafios éticos aparecem, principalmente os ligados a garantia de anonimato e sigilo. Nesse contexto, existem cinco estudos que são considerados hoje casos clássicos que desencadearam intensos debates sobre ética e a questão da confidencialidade nos estudos sociais: a pesquisa de Willian Foot Whyte $(1993,2005)$ sobre a vida social em um subúrbio nos Estados Unidos; as pesquisas sobre parentesco e genética entre os ianomâmis, de Napoleon Chagnon (1968) e Borofsky (2005); a pesquisa sobre práticas homossexuais no espaço público, de Laud Humphreys (2008); a pesquisa sobre aconselhamento genético e equipe de saúde, de Charles Bosk (1992, 2001); e a pesquisa sobre movimentos sociais por direitos de animais, de Rik Scarce (1994, 1995).
Essas pesquisas levantaram questionamentos sobre em quais situações é necessário e ético revelar o nome da fonte pesquisada, em quais contextos podem-se obter dados sem a utilização do termo de consentimento livre e esclarecido e se a confidencialidade deve ser prioridade em estudos que revelam práticas ilegais. A pesquisa sobre movimentos sociais por direitos de animais, de Rik Scarce, contribuiu para esse último questionamento, estimulando o debate a respeito das possibilidades de conduzir estudos sobre temas ilegais sem colocar em risco os participantes da pesquisa.

Diante de tudo isso, ficou evidente que a legislação existente não define os limites entre pesquisa e ação no que se refere a confidencialidade. Nesse sentido, Barbosa e Souza elencam alguns questionamentos não resolvidos sobre o assunto:

O pesquisador deve ser um informante apenas, um denunciador ou interventor na realidade? Em que caso se deve optar pela quebra do sigilo ou anonimato? Que participante privilegiar no caso de conflito de interesses e decisão quanto à quebra deste em casos como violência doméstica, abuso sexual ou questões relacionadas à infração de preceitos dos Direitos Humanos ou legais? Deve-se utilizar o parâmetro legal para decidir sobre a quebra do sigilo e anonimato, ou outras dimensões para além das questões legais devem ser consideradas? É preciso ainda atentar-se para os casos de violência real e violência simbólica, as formas de opressão de populações em situação de vulnerabilidade social e o perigo da denúncia 
que estigmatiza grupos ou pessoas. É preciso discutir mais sobre a limitação da atuação do pesquisador em casos de infração ou violação de Direitos Humanos e legais e sobre como proceder. $^{21}$

Bevilaqua levanta preocupações semelhantes ao realizar uma pesquisa antropológica sobre direitos de consumidores em um município da região metropolitana de Curitiba. Para ela, as normas existentes não ajudam a responder à seguinte questão: "seria ético incorporar à etnografia um material obtido pela observação anônima, mas que permite a identificação dos sujeitos observados e implica danos potenciais a sua reputação?".22

No âmbito de pesquisas em políticas públicas, outra questão deve ser discutida: a expectativa dos pesquisados após a realização de um estudo. De fato, tem-se observado que a realização de pesquisas com grupos vulneráveis sobre os impactos de uma política social cria a esperança de que os problemas revelados serão resolvidos, o que se mostra ainda mais verdade devido aos objetivos dos programas do MDS.
3. Divulgação, acesso e sigilo de informações: a legislação brasileira e os princípios das estatísticas oficiais

Os questionamentos levantados na seção anterior revelam que a extensão das normativas sobre sigilo e confidencialidade para as pesquisas qualitativas na área de ciências humanas pode gerar tensões entre esses princípios éticos e a necessidade de utilizar a informação instrumental para fazer uma intervenção em campo. De fato, a identificação de um problema na oferta de serviço público ou de situações de violação de direitos humanos e constitucionais a partir da realização de pesquisas cria um conflito entre o respeito ao sigilo e à confidencialidade e a necessidade de divulgar essas informações para que medidas possam ser adotadas. Como será tratado nesta seção, a legislação brasileira sobre o assunto, assim como o entendimento do SNE e mesmo decisões judiciais em que esse conflito foi discutido, apontam para a consolidação e o fortalecimento do sigilo e da confidencialidade na realização de pesquisas sociais. 
Como já apresentado na seção 2, as resoluções do CNS (n 196/96 e n 466/2012) já orientam para a impossibilidade de divulgação das informações coletadas, sem consentimento do entrevistado, em pesquisas - sejam elas quantitativas, qualitativas ou etnográficas, nas áreas de saúde ou ciências sociais aplicadas. O sigilo das informações estatísticas também possui fundamentação constitucional, especificamente no art. $5^{\circ}$, inciso XIV, em que "é assegurado a todos o acesso à informação e resguardado o sigilo da fonte, quando necessário ao exercício profissional".

A Lei de Acesso a Informação (LAl, Lei $n^{\circ}$ 12.527, de 18 de novembro de 2011) estimula a transparência na administração pública ao estabelecer como diretrizes, em seu artigo $3^{\circ}$, a publicidade como preceito geral e o sigilo como exceção e a divulgação de informações de interesse público, independentemente de solicitações. Entretanto, no que se refere à divulgação de documentos preparatórios, a LAl "estabelece a discricionariedade da Administração Pública para avaliar a conveniência de publicar ou não a informação antes da tomada de decisões". ${ }^{23}$ De acordo com o Decreto no 7.724/2012, esses documentos são definidos como um conjunto de informações formais que são utilizados como fundamento para a tomada de decisão ou de ato administrativo.

No caso da SAGI, a realização das pesquisas envolve um processo de contratação de pessoa física ou jurídica, que produz insumos que serão analisados e consolidados pela equipe técnica da Secretaria. Como todo relatório técnico de avaliação, produzido por contratação de pessoa física ou jurídica, é um documento preparatório, a LAI confere à SAGI discricionariedade para avaliar se o material pode ser divulgado e acessado por terceiros. A natureza provisória das informações presentes nos documentos preparatórios e a necessidade de a equipe técnica da SAGI realizar uma análise detalhada de seus conteúdos a fim de evitar a incorporação de informações inconsistentes apontam para a inadequação de divulgação de dados provenientes desse tipo de documento.

Cabe enfatizar que a SAGI defende como princípio institucional a valorização da divulgação dos resultados de suas pesquisas. De fato, a Secretaria adota procedimentos que visam promover a disseminação dos resultados e a garantia da transparência das pesquisas realizadas a partir da disponibilização dos microdados de suas pesquisas quantitativas - devidamente desidentificados - e da divulgação do conjunto de informações levantadas pelas avaliações contratadas no sítio eletrônico da Secretaria. Entretanto essa divulgação e compartilhamento de informações ocorrem de forma extremamente cuidadosa em relação à preservação do sigilo e da confidencialidade, já que apenas os relatórios finais das pesquisas são disponibilizados, e os microdados de estudos quantitativos são desidentificados. ${ }^{24}$

Os entendimentos e os princípios do SNE também contribuem para a discussão. O SNE é coordenado pelo IBGE, sendo formado por ministérios e órgãos regionais que produzem informações estatísticas, como o MDS, pelo Instituto Nacional de Estudos e Pesquisas Educacionais Anísio Teixeira (INEP), pelo 
Banco Central do Brasil, entre outros. No caso do IBGE, o órgão possui uma regulamentação própria sobre o assunto: a Lei n 5.534 , de 14 de novembro de 1968, que dispõe sobre a obrigatoriedade da prestação de informações e dá outras providências, estabelecendo no parágrafo único do artigo 10 :

Parágrafo único. As informações prestadas terão caráter sigiloso, serão usadas exclusivamente para fins estatísticos, e não poderão ser objeto de certidão, nem, em hipótese alguma, servirão de prova em processo administrativo, fiscal ou judicial, excetuado apenas, no que resultar de infração a dispositivos desta lei. (grifo nosso)

É importante ressaltar que essa orientação não é uma salvaguarda ao órgão produtor da informação, porém uma proteção ao respondente de que suas informações não serão, sob qualquer hipótese ou natureza de requerimento, objeto de divulgação ou utilização que não para fins estatísticos e de forma agregada. O objetivo é buscar que o informante, protegido por sigilo, apresente as informações mais fidedignas de sua realidade, o que resulta em maior qualidade dos dados coletados. Dessa forma, o IBGE encontra-se legalmente impedido de fornecer informações individualizadas que coleta, no desempenho de suas atribuições, para que sirvam de prova em quaisquer outros processos, judiciais ou administrativos.

Esse entendimento é reforçado pela Comissão de Estatísticas das Nações Unidas, que adotou, em Sessão Especial - ocorrida em abril de 1995 -, os Princípios Fundamentais das Estatísticas Oficiais. O princípio 6 estabelece:

\section{Dados individuais coletados por agências estatísticas para fins de compilação, in- dependentemente se pessoa natural ou pessoa jurídica, devem ser estritamente confidenciais e utilizados exclusivamente com fins estatísticos. ${ }^{25}$}

De fato, as principais orientações internacionais sobre a produção de estatísticas oficiais, como o Handbook of Statistical Organization (produzido pelas ONU), ressaltam que uma das questões mais importantes em uma política do respondente é a preocupação dos órgãos estatísticos em ganhar a confiança dos informantes ao "respeitar suas privacidades e

24 Ver JANNUZZI (2014b) para uma discussão sobre os procedimentos de disseminação de resultados e microdados das pesquisas de avaliação realizadas pela SAGI.

25 TTradução livre de: "Principle 6. Individual data collected by statistical agencies for statistical compilation, whether they refer to natural or legal persons, are to be strictly confidential and used exclusively for statistical purposes".

Revista Brasileira de Monitoramento e Avaliação | Número 7 | Janeiro-Junho de 2014 
manter a confidencialidade que foi prometida a eles quando a informação foi fornecida". ${ }^{26}$

O entendimento da ONU é que o respeito à privacidade deve partir do princípio de que são os indivíduos que detêm as informações sobre eles e, dessa forma, são eles que devem decidir quais informações podem ser disponibilizadas, além de determinar o momento e para quem essas informações serão abertas. A orientação é que mesmo legislações nacionais que requerem a divulgação de informações privadas para finalidades estatísticas devem ser obedecidas apenas quando houver uma necessidade pública primordial.

De acordo com as orientações das Nações Unidas, as informações coletadas por um órgão de estatística não podem ser compartilhadas nem mesmo dentro do governo, não podendo ser divididas com autoridades políticas, agências regulatórias ou com grupos da sociedade civil. O Handbook of Statistical Organization ressalta ainda que, em alguns países, mesmo o Poder Judiciário não pode requisitar informações de agências de estatística.

Esses entendimentos foram incorporados nas práticas do IBGE e nos seus Princípios Oficiais das Estatísticas Oficiais. A confidencialidade é interpretada, pelo órgão, como a anonimidade de informações individualizadas e a não revelação direta ou indireta da identidade do informante com a associação de dados confidenciais. Dessa forma, entende-se que as estatísticas são construções baseadas na agregação de informações individuais, retirando-lhes a individualidade e a identidade e construindo resumos das características relevantes da coleção dos indivíduos.

Em seu estudo sobre a Lei de Acesso a Informação, Cunha Filho e Xavier apresentam uma leitura consonante com esse entendimento em relação à disponibilização de dados oriundos de pesquisas:

No que diz respeito à realização de estatísticas, trata-se de hipótese de exceção à restrição de acesso a informações pessoas destinada a produzir inteligência e aprimorar a elaboração de políticas públicas. Nesses casos, as informações pessoais são entregues ao servidor público, que somente pode divulgá-las de maneira agregada, de modo a não ferir a intimidade das pessoas envolvidas. ${ }^{27}$

Assim, a Lei de Acesso a Informação teve o cuidado de preservar, em seu artigo 60, inciso III, as legislações específicas de sigilo. 0 artigo 30, IV, do Decreto n 7.724/2012, que regulamenta a LAl, manteve o mesmo entendimento.

Com o intuito de preservar a confidencialidade e o sigilo de informações, o IBGE tem adotado diversas práticas: nas pesquisas da área econômica, os dados tabulados são submetidos a tratamento de desidentificação em tabelas de frequência pela regra do patamar, em que não são disponibilizadas informações para células com menos de três informantes; os arquivos de microdados de uso público para pesquisas domiciliares não possuem identificadores, e os dados geográficos são pouco detalhados; no caso de cadastro de produtos e preços, são fornecidos apenas os 
preços médios para produtos genéricos, sem a identificação da marca; etc.

A grande preocupação com o respeito ao sigilo e à confidencialidade das agências que trabalham com pesquisas e com a produção de estatísticas baseia-se em alguns argumentos. Em pesquisas quantitativas e qualitativas, há o compromisso explícito ou implícito entre entrevistador e respondentes de que as informações coletadas servirão para a construção de um diagnóstico geral. Além disso, pressupõe-se, a partir das resoluções do CNS mencionadas, que as informações coletadas não serão utilizadas para finalidade diversa do estabelecido no Termo de Consentimento Livre e Esclarecido.

Tudo isso cria uma expectativa no respondente de que o sigilo e a confidencialidade serão tratados como primordiais pela agência que realiza a pesquisa. Assim, a quebra desses princípios éticos colocaria em risco a legitimidade e a exequibilidade dos levantamentos realizados. Isso levaria a uma situação de racionalização positiva dos respondentes, em que os entrevistados omitem ou declaram informações que se ajustam melhor às normas e condutas social ou legalmente estabelecidas sob o receio de que suas declarações sejam usadas para alguma ação fiscalizatória ou punitiva.

Essa linha argumentativa tem sido acatada, inclusive, por decisões judiciais. Em 2013, o IBGE negou o pedido do Ministério Público (MP) de fornecer informações obtidas em recenseamento sobre a identificação de famílias em que existem crianças e adolescentes que não possuem registro de nascimento. 0 caso teve início no município de Bauru, no estado de São Paulo, quando a imprensa local divulgou, com base em dados do IBGE, a existência se 45 crianças que viviam na área urbana do município e não possuíam certidão de nascimento. Como resultado, a Promotoria da Infância e da Juventude da Comarca requisitou ao IBGE os detalhes das informações sobre essas crianças, a fim de adotar uma postura interventiva. O IBGE negou o pedido, justificando-se pela preservação do sigilo da informação.

Essa situação deu origem a um inquérito, em 14 de junho de 2013, para apurar a postura do IBGE. Em seguida, o MP, com o objetivo de instruir o inquérito em questão e a fim de obter informações semelhantes em nível nacional, solicitou ao IBGE a identificação das famílias em que existiam crianças sem certi-

26 Nações Unidas, 2003, p. 149, tradução livre.

27 CUNHA FILHO \& XAVIER, 2014, p. 328.

Revista Brasileira de Monitoramento e Avaliação | Número 7 | Janeiro-Junho de 2014 
dão de nascimento nos três últimos recenseamentos. O MP baseou-se no argumento de que tal informação era necessária para garantir os direitos constitucionais de uma população vulnerável. Com a negativa do IBGE, o MP entrou com uma ação civil pública para questionar a recusa. A Justiça Federal de Bauru julgou o pedido do MP como inteiramente improcedente. Um ofício do IBGE (CDDI, nº 33/2013) esclarece quais foram as justificativas que embasaram a decisão do Judiciário:

\section{(...) sem a segurança do sigilo estatístico} ninguém vai mais prestar informações estatísticas ao IBGE, porque poderão ser usadas contra os próprios informantes. 0 IBGE depende da acessibilidade às pessoas, do fornecimento espontâneo das informações, para fins estatísticos. Esse é o principal material do IBGE, sem o qual seu trabalho, como instituição, será inviabilizado, pela perda de sua credibilidade.

Embora a salvaguarda legal - a Lei no 5.534 , de 14 de novembro de 1968 - esteja direcionada pelo artigo $1^{028}$ ao IBGE, não se pode esquecer que o arranjo institucional da época da promulgação da referida lei era composto fundamentalmente por este instituto de estatística, situação diferente da atualidade, em que as estatísticas oficiais são produzidas por diversos órgãos e entidades integrantes do Sistema de Estatísticas Nacionais, do qual faz parte o MDS, como produtor de informações relevantes. Portanto, embora o referido dispositivo normativo faça referência apenas ao IBGE, o novo arranjo institucional e a própria orienta- ção das Nações Unidas nos autorizam a fazer uma leitura extensiva, em que todo o sistema de estatística nacional estaria abrangido pela obrigação de proteger a confidencialidade das informações individualizadas coletadas.

Se, entretanto, for oferecida uma interpretação mais restritiva - a de se aplicar apenas ao IBGE a obrigação de proteger as informações individualizadas coletadas -, põe-se em risco não apenas a qualidade das informações coletadas, mas a própria missão institucional das instituições que se dedicam à realização de estudos, pesquisas e avaliações de políticas públicas por meio da coleta de dados primários, como é o caso da SAGI. Ousa-se dizer que a liberação de tais dados pode, inclusive, comprometer a integridade física e patrimonial dos respondentes, pois, para atender às necessidades institucionais, as pesquisas, em geral, levantam informações sobre a renda, o patrimônio, a percepção e o funcionamento de equipamentos públicos implantados pelo Ministério e outras questões que, por sua natureza ou pelo ambiente em que o respondente encontra-se inserido - por exemplo, de conflitos por posse de terra -, são sensíveis.

Afora a questão anteriormente levantada, a disponibilização dos dados individualizados ou que possam ser individualizados pode desvirtuar a própria natureza do trabalho de avaliação, que, conforme o artigo 5 da Portaria MDS 329/2006, ${ }^{29}$ que institui a política de avaliação e monitoramento no âmbito do MDS, não se confunde com fiscalização. 


\section{Considerações finais}

Como apontamos na abertura deste artigo, o Código de Nuremberg, de 1947, inaugurou uma série de normativas que enfatizam o respeito ao sigilo, à confidencialidade e à privacidade na realização de pesquisas. Essas regulamentações representaram um avanço inquestionável no tratamento de questões relacionadas a ética em pesquisa, já que, em momentos anteriores, era prática comum a realização de experimentos sem nenhuma preocupação com o bem-estar e com as possíveis implicações do estudo nas vidas dos indivíduos pesquisados. Dessa forma, a regulamentação internacional atual sobre ética e pesquisa consolidou uma série de princípios - como o consentimento livre e esclarecido e a soberania do sigilo e da confidencialidade - a fim de evitar que essas experiências se repitam. No Brasil, essas orientações foram acolhidas pelo Conselho Nacional de Saúde, que tem aprovado resoluções que reforçam a aplicação do entendimento das normativas internacionais nas pesquisas brasileiras que envolvem seres humanos.
Enquanto o respeito ao sigilo e à confidencialidade encontram-se consolidados e representam, hoje, uma das principais diretrizes do Sistema Nacional de Estatística, muitas questões sobre o papel do pesquisador ainda são alvo de questionamentos variados. Os acadêmicos de pesquisas em humanidades já vêm demostrando seu descontentamento com a falta de clareza das normativas que regem os princípios éticos na realização de pesquisas com seres humanos, uma vez que revela-se extremamente complexa a implementação das regras de sigilo e de confidencialidade, de forma rígida, em pesquisas de natureza qualitativa. Em muitos casos, o pesquisador se vê diante de situações em que é necessário equilibrar duas questões valiosas para a pesquisa social: a confidencialidade e o respeito à não violação de direitos humanos.

Enquanto no meio acadêmico os pesquisadores estão diante de uma situação em que as normativas do CNS não esclarecem, por completo, seu papel em situações próprias de pesquisas de ciências sociais aplicadas, é diferente a situação de órgãos públicos que

28 "Toda pessoa natural ou jurídica de direito público ou de direito privado que esteja sob a jurisdição da lei brasileira é obrigada a prestar as informações solicitadas pela Fundação IBGE para a execução do Plano Nacional de Estatística (Decreto-lei número 161 , de 13 de fevereiro de 1967 , artigo $\left.2^{\circ}, \$^{\circ}\right)^{\prime \prime}$

29 "As ações de avaliação possuem natureza e objetivo distintos das ações de fiscalização e auditoria, com as quais não se confundem."

Revista Brasileira de Monitoramento e Avaliação | Número 7 | Janeiro-Junho de 2014 
realizam pesquisas de avaliação e que compõem o Sistema Nacional de Estatística. Isso ocorre porque, no âmbito do SNE, não restam dúvidas quanto à soberania dos princípios do sigilo e da confidencialidade. Como argumentado na seção 3 deste artigo, exceções a tais princípios inviabilizariam a missão institucional desses órgãos de pesquisa, que se refere à produção, à avaliação e ao monitoramento de informações, e não a ações de fiscalização.

Nesse sentido, os órgãos que compõem o SNE devem adotar como parâmetro central a mencionada Lei no 5.534 de 14 de novembro de 1968, que diz, no parágrafo único do artigo $1^{\circ}$, que "as informações prestadas terão caráter sigiloso, serão usadas exclusivamente para fins estatísticos". Mesmo que seu uso seja mais restrito à produção de análises quantitativas, em um sentido mais amplo, o termo "estatística" refere-se a assuntos do Estado; mais especificamente, à análise de dados sobre o Estado e sua atuação. Nesse sentido, pesquisas de avaliação, inclusive aquelas que se fundamentam em metodologias predominantemente qualitativas, podem ser pensadas como subjugadas às diretrizes do SNE. Outras legislações nacionais, como a LAl e a própria Constituição Federal de 1988, reconhecem a importância do sigilo da fonte e da necessidade de respeito ao mesmo princípio nos casos de produção de informações estatísticas que se propõem aprimorar a elaboração de políticas públicas.

Por fim, é importante ressaltar que as normativas que regulam os princípios do sigilo e da confidencialidade na realização de pesquisas reconhecem a importância da divulgação dos resultados de pesquisas, que devem ter seu acesso facilitado. A ampla divulgação é necessária para subsidiar o aperfeiçoamento das políticas e dos programas governamentais, além de ser essencial para informar o cidadão sobre os resultados de planos governamentais e das estatísticas oficiais do país. Entretanto a transparência e a divulgação de informações provenientes de pesquisas devem ser conciliadas com o sigilo e a confidencialidade. Caso contrário, as agências de pesquisa terão sua credibilidade questionada, e seus trabalhos, inviabilizados. 
BARBOSA, Deborah Rosária; SOUZA, Marilene Proença Rebello. Ética na pesquisa qualitativa: reflexões sobre privacidade, anonimato e confidencialidade. In: GUERREIRO, Iara Coelho Zito; SCHMIDT, Maria Luisa Sandoval; ZICKER, Fabio (org.). Ética nas Pesquisas em Ciências Humanas e Sociais na Saúde. São Paulo: Aderaldo e Rothschild, 2008. p. 237-253.

BEVILAQUA, Ciméa Barbato. Ética e planos de regulamentação da pesquisa: princípios gerais, procedimentos contextuais. In: FLEISCHER, Soraya; SCHUCH, Patrice (orgs.). Ética e Regulamentação na Pesquisa Antropológica. Brasília: Editora UnB, 2010. p. 71-91.

Borofsky R. Yanomami: the fierce controversy and what we can learn from it. Berkeley: University of California Press; 2005

Bosk CL. All God's mistakes: genetic counseling in a pediatric hospital. Chicago: The University of Chicago Press; 1992. 192p; Bosk C. Irony, ethnography, and informed consent. In: Hoffmaster B. Bioethics in social context. Philadelphia: Temple University Press; 2001. p.199-220.

BRASIL. Lei 8.159, de 8 de janeiro de 1991. Dispõe sobre a política nacional de arquivos públicos e privados e dá outras providências. Disponível em: <http://www.planalto.gov.br/ ccivil_03/leis/L8159.htm>.
Lei 5.534, de 14 de março de 1968. Dispõe sobre a obrigatoriedade de prestação de informações estatísticas e dá outras providências. Disponível em: <http://www.planalto.gov. br/ccivil_03/leis/L5534.htm>.

Lei $n^{0} 12.527$, de 18 de novembro de 2011. Regula o acesso a informações previsto no inciso XXXIII do art. $5^{\circ}$, no inciso II do $\S 3^{\circ}$ do art. 37 e no $\S 2^{\circ}$ do art. 216 da Constituição Federal; altera a Lei $\mathrm{n}^{\circ} 8.112$, de 11 de dezembro de 1990; revoga a Lei $n^{0} 11.111$, de 5 de maio de 2005, e dispositivos da Lei $n^{\circ} 8.159$, de 8 de janeiro de 1991; e dá outras providências. Disponível em: <http://www.planalto.gov.br/ccivil_03/_ato2011-2014/2011/lei/l12527.htm>.

Lei $\mathbf{n}^{\circ} \mathbf{8 . 1 1 2}$, de 11 de dezembro de 1990. Dispõe sobre o regime jurídico dos servidores públicos civis da União, das autarquias e das fundações públicas federais. Disponível em: <http://www.planalto.gov.br/ccivil_03/ leis/l8112cons.htm>.

Decreto $\mathrm{n}^{0} \mathbf{7 . 7 2 4}$, de 16 de maio de 2012. Regulamenta a Lei $n^{0} 12.527$, de 18 de novembro de 2011, que dispõe sobre o acesso a informações previsto no inciso $X X X \mid I I I$ do caput do art. $5^{\circ}$, no inciso II do $\$ 3^{\circ}$ do art. $37 \mathrm{e}$ no $\S 2^{\circ}$ do art. 216 da Constituição. Disponível em: <http://www.planalto.gov.br/ccivil_03/_ ato2011-2014/2012/decreto/D7724.htm>.

Chagnon N. Yanomamö: the fierce people. New York: Holt, Rinehart and Winston; 1968. 
CUNHA FILHO, M. C.; XAVIER, V. C. S. Lei de acesso à informação: teoria e prática. Rio de Janeiro: Lumen Juris, 2014.

DALLARI, Sueli Gandolfi. A proteção do direito à intimidade, a confidencialidade e o sigilo das pesquisas em saúde. In: GUERRIERO, lara Coelho Zito; SCHMIDT, Maria Luisa Sandoval; ZICKER, Fabio (org.). Ética nas pesquisas em ciências humanas e sociais na saúde. São Paulo: Hucitec, 2008. p. 53-82.

DINIZ, Debora; GUERREIRO, lara Coelho Zito. Ética na pesquisa social: desafios ao modelo biomédico. RECIIS, Rio de Janeiro; v. 2, Sup. 1, p. Sup. 78-Sup.90, dez. 2008.
Humphreys L. Retrospect: ethical issues in social research. In: Humphreys L. Tearoom trade: impersonal sex in public places. New Brunswick: Aldine Transaction, 2008. p.223-232.

INSTITUTO BRASILEIRO DE GEOGRAFIA E ESTATíSTICA. Ofício CDDI n $33 / 2013$, de 4 de julho de 2013.

JANNUZZI, P. M. Sistemas de Monitoramento e Avaliação de Programas Sociais: revisitando mitos e recolocando premissas para sua maior efetividade na gestão. Revista Brasileira de Monitoramento e Avaliação, Brasília; n. 5, p. 4-27, 2014 a. 
A produção de informação e conhecimento para aprimoramento das políticas de desenvolvimento social: princípios, conceitos e caracterização das pesquisas de avaliação realizadas pela SAGI de 2011 a 2014. Cadernos de Estudos Desenvolvimento Social em Debate, Brasília, n. 16, p. 12-35, 2014 b.

MINAYO, Maria Cecília de Souza. Apresentação. In: GUERREIRO, lara Coelho Zito; SCHMIDT, Maria Luisa Sandoval; ZICKER, Fabio (org.). Ética nas Pesquisas em Ciências Humanas e Sociais na Saúde. São Paulo: Aderaldo e Rothschild, 2008. p. 13-19. Nações Unidas. Handbook of Statistical Organization. $3^{\text {a }}$ ed.New York: United Nations, 2003.

Scarce R. (No) trial (but) tribulations: when courts and ethnography conflict. J Contemp Ethnog. 1994;
23(2):123-149; Scarce R. Scholarly ethics and courtroom antics: where researchers stand in the eyes of the law. Am Sociol. 1995; 26(1):87-112.

VAITSMAN, J.; RODRIGUES, R. W.S; E PAES-SOUZA, R. O Sistema de Avaliação e Monitoramento das Políticas e Programas Sociais: a experiência do Ministério do Desenvolvimento Social e Combate à Fome do Brasil. (Policy Papers, 17). Genebra: Unesco, 2006

Whyte WF. Revisiting Street Corner Society. Sociol. Forum. 1993; 8(2):285-98;

Whyte WF. Sociedade da Esquina. Rio de Janeiro: Jorge Zahar; 2005.

Revista Brasileira de Monitoramento e Avaliação | Número 7 | Janeiro-Junho de 2014 